\title{
The removal of chlorophenols from aqueous solutions using activated carbon adsorption integrated with $\mathrm{H}_{2} \mathrm{O}_{2}$ oxidation
}

\author{
Krzysztof Kuśmierek ${ }^{1}$
}

Received: 14 April 2016/Accepted: 20 May 2016/Published online: 8 June 2016

(C) The Author(s) 2016. This article is published with open access at Springerlink.com

\begin{abstract}
The removal of eight chlorophenols (2-CP, 3-CP, 4-CP, 2,3-DCP, 2,4DCP, 2,5-DCP, 2,6-DCP and 2,4,6-TCP) using adsorption on activated carbon and adsorption in the presence of hydrogen peroxide was investigated. The influence of the $\mathrm{pH}$, activated carbon dosage and hydrogen peroxide concentration were studied. The effects of the chlorine atom position and the chlorine content in the chlorophenol molecules on their degradation were also studied. The results revealed that the integration of the activated carbon and $\mathrm{H}_{2} \mathrm{O}_{2}$ treatment was more effective for the removal of the chlorophenols than using the activated carbon alone. The adsorption kinetics and adsorption efficiency increased with the increasing substitution of chlorine on the aromatic ring. The degradation rate and degradation efficiency of the chlorophenols using the activated carbon integrated with $\mathrm{H}_{2} \mathrm{O}_{2}$ decreased with the increasing chlorine atoms in the molecule. The combination of the activated carbon with hydrogen peroxide may significantly enhance the process and could offer an interesting alternative in wastewater treatment.
\end{abstract}

Keywords Chlorophenol · Activated carbon · Hydrogen peroxide · Adsorption

\section{Introduction}

Chlorophenols (CPs) are among the most widespread pollutants of wastewater and natural waters. The presence of chloroorganic compounds in the aqueous environment including drinking water $[1,2]$ is a consequence of their use in a variety of industrial processes such as wood, fibre, paint and leather preservatives, for the manufacturing of pesticides and resins as well as for water disinfection [3].

Krzysztof Kuśmierek

krzysztof.kusmierek@wat.edu.pl

1 Institute of Chemistry, Military University of Technology, 00-908 Warsaw, Poland 
Chlorophenols cause serious environmental problems, due to their high toxicity, strong odor emission, persistence in the environment and carcinogenic properties [4]. Thus, it is important to prevent their release into the environment and to study methods for their removal from contaminated sites.

Several methods are available for the removal of chlorinated phenols from water. Among them, biodegradation [5], oxidation by advanced oxidation processes [6] and adsorption [7, 8] are the most widely used. Advanced oxidation processes (AOPs) are based on the generation and use of powerful hydroxyl radicals ( $\mathrm{OH}$ ) by means of chemical, photochemical or photocatalytic methods (Fenton, photoFenton, $\mathrm{H}_{2} \mathrm{O}_{2} / \mathrm{O}_{3}, \mathrm{H}_{2} \mathrm{O}_{2} / \mathrm{UV}, \mathrm{UV} / \mathrm{O}_{3}, \mathrm{UV} / \mathrm{TiO}_{2}$ ) [6]. Adsorption has proven to be one of the most attractive and effective methods for removing chlorophenols from water, due to its low maintenance costs, high efficiency, simplicity of operation as well as the no or lower generation of toxic substances. Activated carbons (AC) are now the most commonly used adsorbents of the proven adsorption efficiency for organic pollutants due to their high surface area, pore volume, and pore size distribution [7, 8]. Activated carbons have also been used as heterogeneous catalysts and supports of catalysts [9]. It is well known that the hydrogen peroxide can be activated by AC (Eqs. 1 and 2) forming reactive free radicals that are able to oxidize organic contaminants.

$$
\begin{gathered}
\mathrm{AC}+\mathrm{H}_{2} \mathrm{O}_{2} \rightarrow \mathrm{AC}^{+}+\mathrm{OH}^{-}+\mathrm{OH} \\
\mathrm{AC}^{+}+\mathrm{H}_{2} \mathrm{O}_{2} \rightarrow \mathrm{AC}+\mathrm{HO}_{2}+\mathrm{H}^{+}
\end{gathered}
$$

In recent years, several authors reported that $\mathrm{H}_{2} \mathrm{O}_{2}$ in the presence of activated carbon could oxidize some pollutants such as methyl tert-butyl ether [10], trichloroethene [10], fulvic acids [11], dyes [12, 13], paraquat [14], cyanide [15], ethylene glycol [16], ampicillin [17] and chlorophenols [10, 18-20].

The effectiveness of the organic compound degradation depends on many factors, including the $\mathrm{pH}$, temperature, $\mathrm{H}_{2} \mathrm{O}_{2}$ concentration as well as the physicochemical properties of the activated carbons, which affect the decomposition of the hydrogen peroxide. The $\mathrm{H}_{2} \mathrm{O}_{2}$ decomposition on the activated carbon is followed by the exchange of a hydroxyl group at the AC surface with a hydrogen peroxide anion (Eq. 3). The formed surface peroxide is regarded as having an increased oxidation potential which enables the decomposition of another hydrogen peroxide molecule releasing oxygen and regenerating the activated carbon group (Eq. 4) [10].

$$
\begin{aligned}
& \mathrm{AC}-\mathrm{OH}+\mathrm{H}^{+} \mathrm{OOH}^{-} \rightarrow \mathrm{AC}-\mathrm{OOH}+\mathrm{H}_{2} \mathrm{O} \\
& \mathrm{AC}-\mathrm{OOH}+\mathrm{H}_{2} \mathrm{O}_{2} \rightarrow \mathrm{AC}-\mathrm{OH}+\mathrm{H}_{2} \mathrm{O}+\mathrm{O}_{2}
\end{aligned}
$$

The degradation of the hydrogen peroxide depends on the nature of the activated carbon surface. The activated carbons of basic character promote a faster hydrogen peroxide decomposition whereas the presence of acidic surface oxygen groups inhibits the reaction $[12,18,21]$. Huang et al. [19] found that the decomposition of the $\mathrm{H}_{2} \mathrm{O}_{2}$ decreased with an increasing content of the acidic groups on the AC 
surface. The catalytic activity of AC toward the 4-CP followed the inverse sequence of the activity toward the $\mathrm{H}_{2} \mathrm{O}_{2}$. The acidic functional groups on the AC surface, decreased the loss of the $\mathrm{H}_{2} \mathrm{O}_{2}$ and reduced the effect of surface scavenging resulting in the increase of the 4-CP degradation efficiency [19]. A similar phenomenon was observed in the oxidation of the 2-chlorophenol [20]. Lücking et al. [18] reported that the decomposition of $\mathrm{H}_{2} \mathrm{O}_{2}$ during the oxidation of 4-chlorophenol in the $\mathrm{AC} / \mathrm{H}_{2} \mathrm{O}_{2}$ system was slower than in the absence of 4-CP. This fact was a consequence of the adsorption of 4-CP which reduces the surface area of the AC available for the decomposition of the hydrogen peroxide. The decreasing of the particle size of the activated carbon also accelerates the kinetics of the hydrogen peroxide decomposition [22]. The porosity of the activated carbons (the extended surface areas or large pore volumes) did not enhance the decomposition of $\mathrm{H}_{2} \mathrm{O}_{2}$, but in fact reduced it $[19,21]$. Nevertheless, the catalytic activity of some carbonaceous materials (carbon blacks and carbon nanotubes) toward 2-CP was enhanced with an increase in the specific surface area of the catalysts [20].

In most of the works, the authors studied the oxidation by hydrogen peroxide in the presence of the activated carbon or compared the catalytic properties of various activated carbons. These studies, however, concern only one compound (comparative studies for several compounds were rare). The effectiveness of the $\mathrm{AC} / \mathrm{H}_{2} \mathrm{O}_{2}$ process was investigated only for a few selected chlorophenols including 2-CP [20], 4-CP [18, 19] and 2,4,5-trichlorophenol [10]. However, to the best knowledge, the other chlorophenols were not studied and were not compared to each other.

The aim of this study was to investigate the adsorption as well as the adsorption integrated with the $\mathrm{H}_{2} \mathrm{O}_{2}$ oxidation of eight chlorophenols. The effects of the $\mathrm{pH}$, activated carbon dosage and hydrogen peroxide concentration were studied. The effects of the chlorine atom position and chlorine content in the chlorophenols molecules on their degradation were evaluated and discussed.

\section{Materials and methods}

\section{Chemicals and reagents}

The chlorophenols: 2-chlorophenol (2-CP), 3-chlorophenol (3-CP), 4-chlorophenol (4-CP), 2,3-dichlorophenol (2,3-DCP), 2,4-dichlorophenol (2,4-DCP), 2,5dichlorophenol (2,5-DCP), 2,6-dichlorophenol (2,6-DCP) and 2,4,6-trichlorophenol (2,4,6-TCP) were purchased from Sigma-Aldrich (St. Louis, USA). Sodium hydroxide, hydrogen peroxide $(30 \%)$, sulfuric acid $(95 \%)$, acetic acid (99\%) and HPLC-grade acetonitrile were from Avantor Performance Materials (Gliwice, Poland).

The L2S powdered activated carbon (Ceca, France) was used in this experiment. The specific surface area $\left(S_{\mathrm{BET}}\right)$, the micropore $\left(V_{\mathrm{mi}}\right)$ and the mesopore $\left(V_{\mathrm{me}}\right)$ volumes were $925 \mathrm{~m}^{2} \mathrm{~g}^{-1}, 0.245$ and $0.235 \mathrm{~cm}^{3} \mathrm{~g}^{-1}$ [23]. Prior to use, the activated carbon was dried in an oven at $120{ }^{\circ} \mathrm{C}$ to a constant weight and kept in a desiccator for further study. 


\section{Adsorption/oxidation procedure}

The experiments were carried out in Erlenmeyer flasks containing $0.05 \mathrm{~L}$ of chlorophenol solution $\left(0.5 \mathrm{mmol} \mathrm{\textrm {L } ^ { - 1 }}\right)$ as well as appropriate amounts of hydrogen peroxide and activated carbon at various $\mathrm{pH}$ (3-11) and an agitation speed of $200 \mathrm{rpm}$ at $25{ }^{\circ} \mathrm{C}$. The effects of the $\mathrm{pH}$, activated carbon dosage and hydrogen peroxide concentration were investigated. These experiments were conducted only for the 3-chlorophenol. It was established that the best conditions for the degradation of 3-CP will be optimal also for the other chlorophenols. Aqueous samples were taken at different intervals of time and the concentrations of chlorophenols were measured by high performance liquid chromatography. The amounts of adsorption/oxidation at the time $t\left(q_{\mathrm{t}}, \mathrm{mmol} \mathrm{g}^{-1}\right)$ and at equilibrium $\left(q_{\mathrm{e}}, \mathrm{mmol} \mathrm{g}^{-1}\right)$ were calculated by the following equations:

$$
\begin{aligned}
& q_{\mathrm{t}}=\frac{\left(\mathrm{C}_{0}-\mathrm{C}_{\mathrm{t}}\right) \mathrm{V}}{m} \\
& q_{\mathrm{e}}=\frac{\left(\mathrm{C}_{0}-\mathrm{C}_{\mathrm{e}}\right) \mathrm{V}}{m}
\end{aligned}
$$

Here $C_{0}, C_{\mathrm{t}}$ and $C_{\mathrm{e}}$ are the initial concentration, concentration at time $t$ and equilibrium concentration (after $6 \mathrm{~h}$ ) of chlorophenol in the solution $\left(\mathrm{mmol} \mathrm{L}^{-1}\right), V$ is the volume of the solution (L) and $m$ is the mass of the activated carbon $(\mathrm{g})$.

All the experiments were carried out in triplicate under identical conditions and the average values were used for further calculations. The mean and standard deviation of the three replicates were reported and the data obtained were analyzed using $t$ test and/or ANOVA with a Tukey test. The differences between any pair of the treatment means were tested using the least significant difference test with the significance level at 0.05 .

\section{Analytical method}

The concentrations of the chlorophenols were measured by high performance liquid chromatography with UV detection (Shimadzu LC-20, Kyoto, Japan). The chromatographic conditions were as follows: mobile phase-acetonitrile/water adjusted to $\mathrm{pH} 3.0$ with acetic acid $(50 / 50, v / v)$, flow rate $0.25 \mathrm{~mL} \mathrm{~min}^{-1}$ and analytical wavelength $280 \mathrm{~nm}$. The chromatographic analyses were carried out on a Phenomenex Luna C18, $2.0 \times 150$ mm, $3 \mu \mathrm{m}$ column (Torrance, USA).

\section{Results and discussion}

In order to investigate the optimal chlorophenol degradation conditions, the effects of the $\mathrm{pH}$, the activated carbon dosage and the hydrogen peroxide concentration were studied. 3-Chlorophenol was used as a model compound throughout the study. 


\section{Effect of pH}

The effect of the $\mathrm{pH}$ on the 3-CP degradation was studied by varying the initial $\mathrm{pH}$ of the solutions from $\mathrm{pH} 3$ to 11 . The $\mathrm{pH}$ was adjusted (prior to the addition of the $\mathrm{H}_{2} \mathrm{O}_{2}$ and the AC) using $0.1 \mathrm{~mol} \mathrm{~L}^{-1} \mathrm{H}_{2} \mathrm{SO}_{4}$ or $0.1 \mathrm{~mol} \mathrm{~L}^{-1} \mathrm{NaOH}$ and was measured using a $\mathrm{pH}$ meter. The mass of the $\mathrm{AC}$ was fixed at $0.01 \mathrm{~g}$ and the initial concentrations of 3-CP and $\mathrm{H}_{2} \mathrm{O}_{2}$ were 0.5 and $5.0 \mathrm{mmol} \mathrm{L}^{-1}$, respectively. The results are presented in Fig. 1.

For the description of the experimental data, the equations of the pseudo-first [24] (Eq. 7) and pseudo-second order [25] (Eq. 8) were considered.

$$
\begin{gathered}
\log \left(q_{\mathrm{e}}-q_{\mathrm{t}}\right)=\log q_{\mathrm{e}}-\frac{k_{1}}{2.303} t \\
\frac{t}{q_{\mathrm{t}}}=\frac{1}{k_{2} q_{\mathrm{e}}^{2}}+\frac{1}{q_{\mathrm{e}}} t
\end{gathered}
$$

Here $k_{1}$ is the pseudo-first order rate constant $\left(\mathrm{h}^{-1}\right)$ and $k_{2}$ is the pseudo-second order rate constant $\left(\mathrm{g} \mathrm{mmol}^{-1} \mathrm{~h}^{-1}\right)$. The values of $k_{1}$ and $k_{2}$ were calculated from the plots of $\log \left(q_{\mathrm{e}}-q_{\mathrm{t}}\right)$ versus $t$ and $t / q_{\mathrm{t}}$ versus $t$, respectively. All of the results obtained from the pseudo-first order kinetic model were weaker in each case, and therefore they were not taken into account and are not shown. For the comparison and interpretation of the results only the pseudo-second order rate constants were used.

The degradation rate of the 3-CP decreased with an increase in the $\mathrm{pH}$ from 3 to 11. The $k_{2}$ values obtained for the initial $\mathrm{pH}$ solutions of $3,5,7,9$ and 11 were $0.775,0.554,0.513,0.267$ and $0.156 \mathrm{~g} \mathrm{mmol}^{-1} \mathrm{~h}^{-1}$. As can be seen, the $\mathrm{pH}$ affects not only the degradation rate of 3-CP but also its effectiveness. After $6 \mathrm{~h}$, at $\mathrm{pH} 3$, about $80 \%$ of 3-CP was removed while at $\mathrm{pH} 11$ only $10 \%$.

Fig. 1 Effect of $\mathrm{pH}$ on the removal of 3-chlorophenol by $\mathrm{AC} / \mathrm{H}_{2} \mathrm{O}_{2}$. Experimental conditions: $[3-\mathrm{CP}]=0.5 \mathrm{mmol}$ $\mathrm{L}^{-1},\left[\mathrm{H}_{2} \mathrm{O}_{2}\right]=5.0 \mathrm{mmol} \mathrm{L}{ }^{-1}$, $\mathrm{AC}=0.01 \mathrm{~g}$, temperature: $25^{\circ} \mathrm{C}$

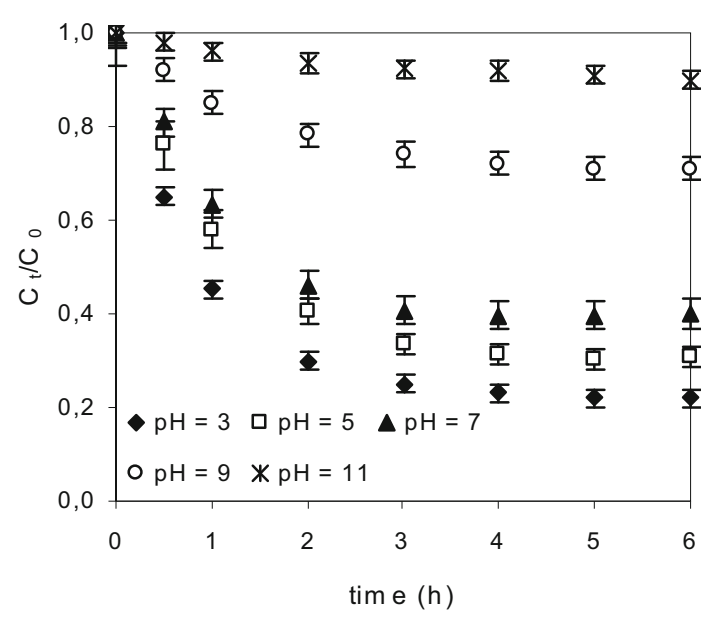


The relationship between the initial solution $\mathrm{pH}$ and the adsorption/oxidation of 3-CP at equilibrium $\left(q_{\mathrm{e}}\right)$ is presented in Fig. 2. For comparative purposes, the experiments of the 3-CP adsorption on the activated carbon in the absence of hydrogen peroxide were also carried out under the same conditions (Fig. 2).

The removal of the 3-CP in the absence of $\mathrm{H}_{2} \mathrm{O}_{2}$ was almost constant at the acidic $\mathrm{pH}$ range of 3-7 and decreased with the further increasing in the $\mathrm{pH}$ (from $\mathrm{pH} 7$ to 11). The $q_{\mathrm{e}}$ value decreased with an increase in the $\mathrm{pH}$ from 3 to 11 from 0.997 to $0.190 \mathrm{mmol} \mathrm{g}^{-1}$. This dependence is associated with the $\mathrm{pK}_{\mathrm{a}}$ of the adsorbate (8.8) and $\mathrm{pH}_{\mathrm{PZC}}$ of the adsorbent. The point of zero charge $\left(\mathrm{pH}_{\mathrm{PZC}}\right)$ was determined by the $\mathrm{pH}$ drift method and was found to be 7.0. At a $\mathrm{pH}$ greater than the $\mathrm{pK}_{\mathrm{a}}$ value, 3-CP existed predominantly in anionic forms as a negatively charged phenolate anions. At the $\mathrm{pH}$ below the $\mathrm{pH}_{\mathrm{PZC}}$, the surface of the $\mathrm{AC}$ was positively charged, while at a $\mathrm{pH}$ greater than $\mathrm{pH}_{\mathrm{PZC}}$, the surface had a net negative charge. The results showed that the non-dissociated form of 3-CP was preferred by the positively charged surface of the activated carbon. The large reduction in 3-CP adsorption at highly basic conditions can be attributed to the electrostatic repulsion between the negatively charged AC and the dissociated 3-CP molecules. Similar results were reported for the adsorption of the 4-chlorophenol on the activated carbon prepared from rattan sawdust [26] and the Norit R3-ex granular activated carbon [27].

The influence of the $\mathrm{pH}$ on 3-CP removal by the $\mathrm{AC} / \mathrm{H}_{2} \mathrm{O}_{2}$ is different, because the $\mathrm{pH}$ of the solution affects the nature of the chemical surface of the activated carbon but also the stability of the hydrogen peroxide. In acidic media, hydrogen peroxide is more stable; the higher decomposition is observed under the basic conditions. These facts explain the removal of 3-CP at different $\mathrm{pH}$ (Fig. 2). The results showed that 3-CP degradation using activated carbon and $\mathrm{H}_{2} \mathrm{O}_{2}$ decreased by increasing the $\mathrm{pH}$. The best results were observed in the acid environment ( $\mathrm{pH} 3)$ as a result of the higher stability and the higher redox potential of the hydrogen peroxide [18] as well as the high adsorption capacity of the activated carbon at low $\mathrm{pH}$ values. Similar observations (the most effective degradation of the 4-CP by AC/

Fig. 2 The relationship between the solution $\mathrm{pH}$ and the removal of 3-CP at equilibrium (after $6 \mathrm{~h}$ ) on activated carbon (AC) and activated carbon in the presence of $\mathrm{H}_{2} \mathrm{O}_{2}$. Experimental conditions: $[3-\mathrm{CP}]=0.5 \mathrm{mmol} \mathrm{L}^{-1}$, $\left[\mathrm{H}_{2} \mathrm{O}_{2}\right]=5.0 \mathrm{mmol} \mathrm{L}^{-1}$, $\mathrm{AC}=0.01 \mathrm{~g}$, temperature: $25^{\circ} \mathrm{C}$

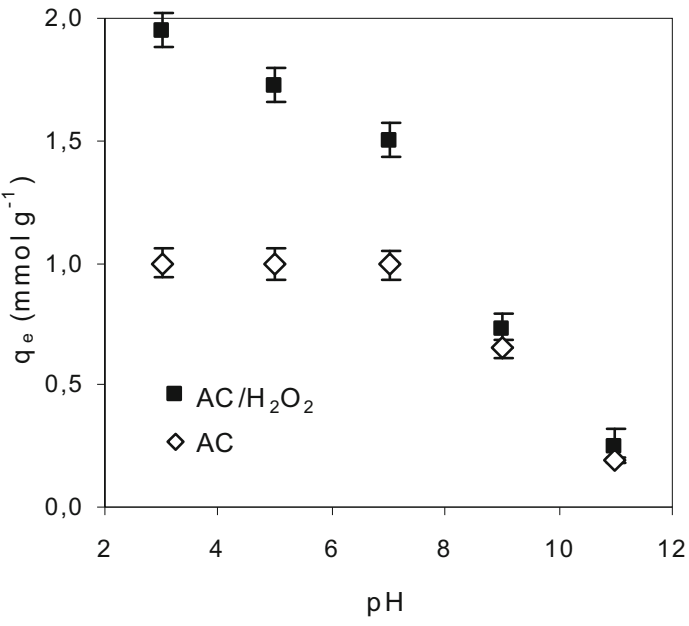


$\mathrm{H}_{2} \mathrm{O}_{2}$ at $\mathrm{pH}$ 3) have previously been described by Lücking et al. [18]. Khorramfar et al. [13] also reported that the Acid Red 18, Direct Red 80 and Reactive Red 194 dyes oxidation using the $\mathrm{AC} / \mathrm{H}_{2} \mathrm{O}_{2}$ increased by decreasing the $\mathrm{pH}$.

Since the lower $\mathrm{pH}$ favored the removal efficiency, in the following, chlorophenols degradation were studied at $\mathrm{pH} 3$.

\section{Effect of activated carbon dose}

To investigate the effect of the activated carbon dosage on the chlorophenol degradation, different amounts of $\mathrm{AC}(0.005,0.010,0.015$ and $0.020 \mathrm{~g})$ were added to the Erlenmeyer flasks containing $0.05 \mathrm{~L} \mathrm{3-CP}$ solution $\left(0.5 \mathrm{mmol} \mathrm{L}{ }^{-1}\right)$ and hydrogen peroxide $\left(5.0 \mathrm{mmol} \mathrm{L}^{-1}\right)$. The $\mathrm{pH}$ of the solution was set as 3.0 prior to the addition of the $\mathrm{H}_{2} \mathrm{O}_{2}$ and $\mathrm{AC}$. The results are presented in Fig. 3.

The removal efficiency increased with an increase in the initial AC dosage from $50 \%(0.005 \mathrm{~g})$ to about $85 \%(0.02 \mathrm{~g})$. The degradation kinetics followed a pseudosecond order and the $k_{2}$ rate constants were found to increase with the AC dosage $\left(0.281,0.911,1.522\right.$ and $1.788 \mathrm{~g} \mathrm{mmol}^{-1} \mathrm{~h}^{-1}$ for the initial AC concentration of $0.005,0.010,0.015$ and 0.020$)$. An increase in 3-CP removal with the AC dosage can be attributed to the greater surface area and the availability of more adsorption sites. Moreover, the higher AC concentration leads to an increase in the number of active catalytic sites available for $\mathrm{H}_{2} \mathrm{O}_{2}$ decomposition.

\section{Effect of $\mathrm{H}_{2} \mathrm{O}_{2}$ concentration}

The effect of the hydrogen peroxide concentration was studied with an initial 3-CP concentration of $0.5 \mathrm{mmol} \mathrm{L}^{-1}$, for different $\left[\mathrm{H}_{2} \mathrm{O}_{2}\right] /[3-\mathrm{CP}]$ molar ratios equal to 1 , 10, 50 and 100. The AC concentration was constant for all of the experiments $(0.015 \mathrm{~g})$ and the $\mathrm{pH}$ was 3.0. It can be observed in Fig. 4 that the removal efficiency of 3-CP raises with the increase of the $\mathrm{H}_{2} \mathrm{O}_{2}$ molar excess from 1 to 10. A

Fig. 3 Effect of activated carbon dosage on degradation of 3-CP using $\mathrm{AC} / \mathrm{H}_{2} \mathrm{O}_{2}$.

Experimental conditions: [3-

$\mathrm{CP}]=0.5 \mathrm{mmol} \mathrm{L}^{-1}$,

$\left[\mathrm{H}_{2} \mathrm{O}_{2}\right]=5.0 \mathrm{mmol} \mathrm{L}^{-1}$, $\mathrm{pH}=3.0$, temperature: $25^{\circ} \mathrm{C}$

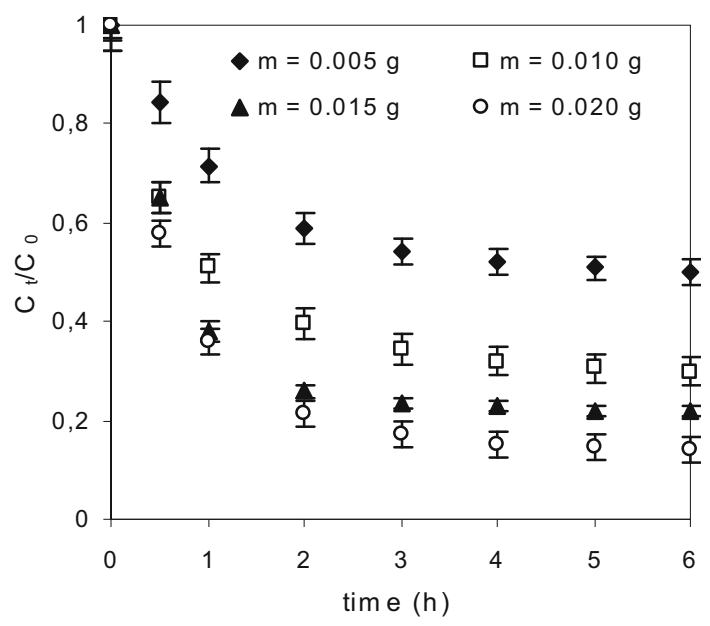


Fig. 4 Effect of hydrogen peroxide concentration on 3-CP removal using $\mathrm{AC} / \mathrm{H}_{2} \mathrm{O}_{2}$.

Experimental conditions: [3$\mathrm{CP}]=0.5 \mathrm{mmol} \mathrm{L}^{-1}$, $\mathrm{AC}=0.015 \mathrm{~g}, \mathrm{pH} 3.0$, temperature: $25^{\circ} \mathrm{C}$

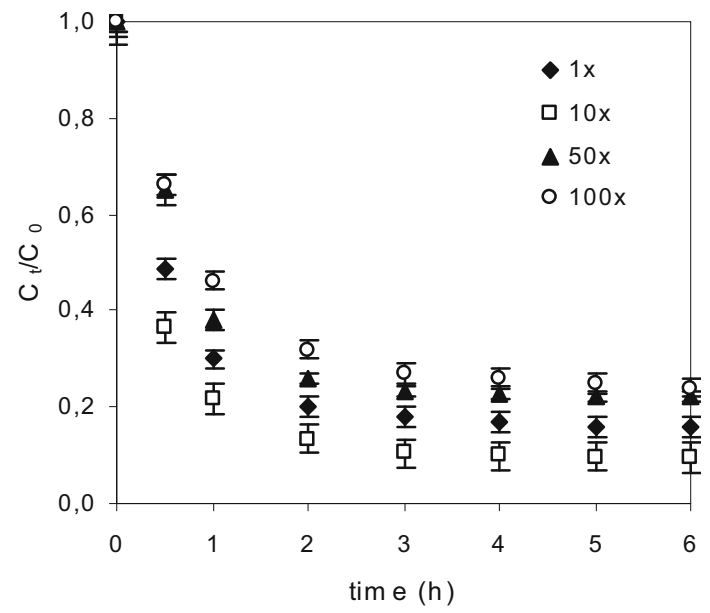

further increase of the $\mathrm{H}_{2} \mathrm{O}_{2}$ dosage did not achieve a higher removal rate and efficiency. For the molar ratios of 1, 10, 50 and 100,3-CP removal after $6 \mathrm{~h}$ was 84, 91, 78 and $76 \%$, and the $k_{2}$ values were as follows: $2.430,3.275,1.522$ and $1.223 \mathrm{~g} \mathrm{mmol}^{-1} \mathrm{~h}^{-1}$. These results agree with the earlier studies, which reported that an excessive concentration of hydrogen peroxide decreases the degradation efficiency of the organic compounds including ampicillin [17] and paraquat [14] by $\mathrm{AC} / \mathrm{H}_{2} \mathrm{O}_{2}$. It may be due to the fact that some of the organic compounds and oxidation by-products were quickly removed by the adsorption and did not react with the $\mathrm{H}_{2} \mathrm{O}_{2}$, so they did not consume $\mathrm{H}_{2} \mathrm{O}_{2}$. Also, the more resistant by-products generated during the oxidation process could only be removed by the activated carbon, and as a result, a further increase of the $\mathrm{H}_{2} \mathrm{O}_{2}$ concentration did not improve the removal efficiency [17]. Dhaouadi and Adhoum [14] reported that the decrease in the oxidation efficiency observed at high $\mathrm{H}_{2} \mathrm{O}_{2}$ dosages may be due to its scavenging effect towards the hydroxyl radicals according to the following reactions:

$$
\begin{gathered}
\mathrm{H}_{2} \mathrm{O}_{2}+\mathrm{OH} \leftrightarrow \mathrm{HO}_{2}+\mathrm{H}_{2} \mathrm{O} \\
\mathrm{HO}_{2}+\mathrm{OH} \leftrightarrow \mathrm{O}_{2}+\mathrm{H}_{2} \mathrm{O}
\end{gathered}
$$

This phenomenon causes a dramatic loss of hydrogen peroxide leading to oxidation inefficiency [14]. A negative impact of the excessive $\mathrm{H}_{2} \mathrm{O}_{2}$ concentration has previously been described by $\mathrm{Ku}$ et al. [28] who studied the decomposition rate of the 3-CP by sonolysis in the presence of hydrogen peroxide. The degradation rate of 3-CP $\left(20 \mathrm{mg} \mathrm{L}^{-1}\right)$ was kept high in the presence of $700 \mathrm{mg} \mathrm{L}^{-1}$ of $\mathrm{H}_{2} \mathrm{O}_{2}$. However, the degradation rate was slightly decreased for the experiment conducted with the presence of $1000 \mathrm{mg} \mathrm{L}^{-1}$ of hydrogen peroxide [28]. On that basis, a $5.0 \mathrm{mmol} \mathrm{L}{ }^{-1}$ concentration of $\mathrm{H}_{2} \mathrm{O}_{2}$ was used for subsequent studies. 


\section{Removal of chlorophenols by $\mathrm{AC}$ and $\mathrm{AC} / \mathrm{H}_{2} \mathrm{O}_{2}$}

The removal efficiency and kinetics of eight chlorophenols in aqueous solution were investigated. The effects of the chlorine position and chlorine content in the chlorophenol molecules on their degradation were evaluated. All of the experiments were conducted under the same conditions (temperature $25^{\circ} \mathrm{C}$, agitation rate $200 \mathrm{rpm}, \mathrm{pH} 3.0$, mass of the $\mathrm{AC}=0.015 \mathrm{~g}$, initial concentration of the $\mathrm{CP}=0.5 \mathrm{mmol} \mathrm{L}{ }^{-1}$, initial concentration of $\mathrm{H}_{2} \mathrm{O}_{2}=5.0 \mathrm{mmol} \mathrm{L}^{-1}$ ). The noncatalytic oxidation with $\mathrm{H}_{2} \mathrm{O}_{2}$, the adsorption on the activated carbon, as well as the oxidation with $\mathrm{H}_{2} \mathrm{O}_{2}$ in the presence of the activated carbon were studied. The hydrogen peroxide decomposition by the activated carbon was not tested because in all of the experiments only one AC was used (L2S Ceca).

The oxidation of the chlorophenols with $\mathrm{H}_{2} \mathrm{O}_{2}$ in the absence of the activated carbon was not significant [data not shown]. During the considered period of time $(6 \mathrm{~h})$, the amounts of the CPs in the solution were constant. The concentrations varied $\pm 3 \%$, which was due to the measurement error rather than the oxidation of the chlorophenols by the hydrogen peroxide. The removal of the chlorophenols by the $\mathrm{AC}$ and the $\mathrm{AC} / \mathrm{H}_{2} \mathrm{O}_{2}$ as a function of time is presented in Fig. 5. The values of the $k_{2}$ kinetic constants, the $q_{\mathrm{e}}$ and percentage removal after $6 \mathrm{~h}$ are listed in Table 1.

The results revealed that the increasing of the degree of chlorine substitution on the phenol ring increased the adsorption rate and adsorption efficiency of the CPs on the activated carbon. The adsorption of the CPs increased in the order monochlorophenols $<$ dichlorophenols $<$ trichlorophenol, which was correlated with the respective increase in the molecular mass, hydrophobicity and the decrease in the solubility. Similar results were reported by other authors [29-32]. The differences in the $k_{2}$ and $q_{\mathrm{e}}$ values between the mono-, di- and TCP were statistically significant. However, the differences between the individual monochlorophenols (2$\mathrm{CP}, 3-\mathrm{CP}$ and 4-CP) as well as the dichlorophenols (2,3-DCP, 2,4-DCP, 2,5-DCP and 2,6-DCP) were not significantly different (ANOVA-Tukey test).

The combination of the activated carbon and hydrogen peroxide increased the removal of the chlorophenols in comparison with the single AC adsorption. The degradation order of the $\mathrm{CPs}$ by $\mathrm{AC} / \mathrm{H}_{2} \mathrm{O}_{2}$ was $3-\mathrm{CP}>4-\mathrm{CP}>2-\mathrm{CP}>2,3$ $\mathrm{DCP} \geq 2,5-\mathrm{DCP} \geq 2,6-\mathrm{DCP} \geq 2,4-\mathrm{DCP}>2,4,6-\mathrm{TCP}$. For comparison, Tang and Huang [33] reported that the oxidation rates decreased in the order 3-CP $>2$ $\mathrm{CP}>4-\mathrm{CP}>2,5$-DCP $>3,5-\mathrm{DCP}>2,3$-DCP $>2,6$-DCP $>2$, 4-DCP $>2,4,6-$ TCP for Fenton's reagent. The oxidation kinetics of the chlorophenols in the aqueous solution with the potassium permanganate followed the sequence 2-CP $>2,6-\mathrm{DCP}>4-\mathrm{CP}>2,4-\mathrm{DCP}>3-\mathrm{CP}[34]$. For the single photodecomposition produced by the polychromatic UV irradiation and oxidation by the combined $\mathrm{UV} / \mathrm{H}_{2} \mathrm{O}_{2}$ system, Benitez et al. [35] found that the oxidation rates decrease in the order 4-CP $>2,4-\mathrm{DCP}>2,4,6-\mathrm{TCP}$. On the other hand, Hugül et al. [36] reported that the degradation order of CPs was $2,4,6-\mathrm{TCP} \geq 2,4-\mathrm{DCP}>2-\mathrm{CP}$ for the UVcatalyzed oxidation with the $\mathrm{H}_{2} \mathrm{O}_{2}$. Zhou et al. [37] described the oxidation of the chlorophenols with the $\mathrm{H}_{2} \mathrm{O}_{2}$ catalyzed by the $\mathrm{Cu}-\mathrm{Al}$ hydrotalcite/clay composite. They found that the content and position of the chlorine on the aromatic ring had 

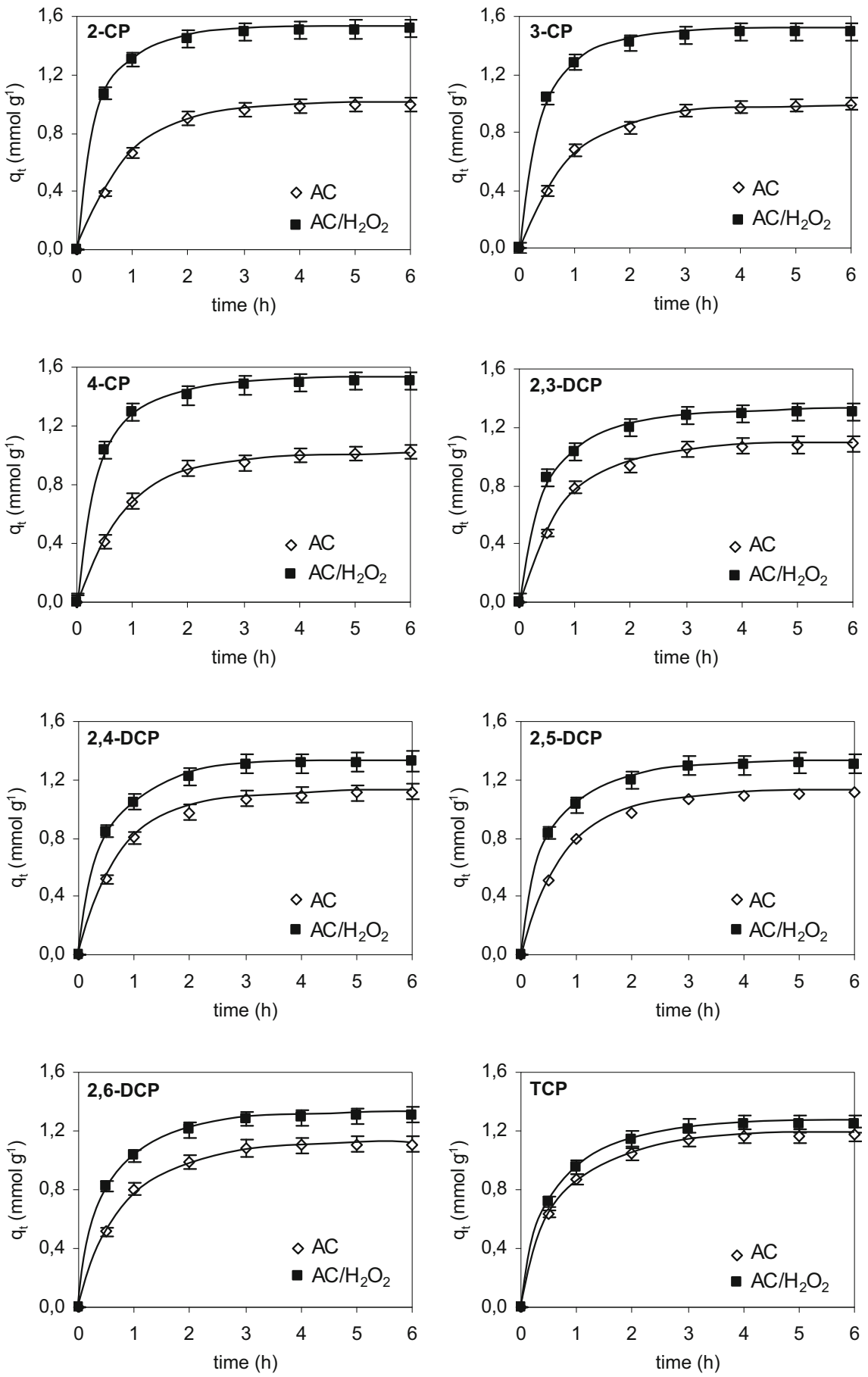
4Fig. 5 Degradation rate of chlorophenols by adsorption on activated carbon (AC) and adsorption/ oxidation using activated carbon in the presence of hydrogen peroxide $\left(\mathrm{AC} / \mathrm{H}_{2} \mathrm{O}_{2}\right)$. Experimental conditions: $[\mathrm{CP}]=0.5 \mathrm{mmol} \mathrm{L}{ }^{-1},\left[\mathrm{H}_{2} \mathrm{O}_{2}\right]=5.0 \mathrm{mmol} \mathrm{L}^{-1}, \mathrm{AC}=0.015 \mathrm{~g}, \mathrm{pH}=3.0$, temperature: $25^{\circ} \mathrm{C}$

significantly different effects on the oxidation rate of the CPs, with the rate sequence of $\quad 3-\mathrm{CP}>2-\mathrm{CP}>4-\mathrm{CP}>3,5-\mathrm{DCP}>3,4-\mathrm{DCP}>2,5-\mathrm{DCP}>2,4-\mathrm{DCP}>2,6-$ DCP $>2,4,5-T C P$. Simon et al. [38] investigated the effect of chlorine substituents on the oxidation of all 19 chlorophenols by cerium(IV). The oxidation rate constants of the chlorophenols (used in this paper only) decreased in the order 4-CP $>3$ $\mathrm{CP}>2,4,6$-TCP $>2,5$-DCP $>2,3$-DCP $\geq 2$-CP $>2$,4-DCP $>2$,6-DCP. 2,4,6Trichlorophenol was removed faster than all of the dichlorophenols and 2-CP, but the authors found that 2,4,6-TCP showed a substantially different behavior than other chlorophenols. In general, the ortho- substitution decreased the reactivity, the meta- substitution had no significant effect on the reactivity while the parasubstitution increased the reactivity in the cerium(IV) oxidation [38].

These examples suggest that the chlorine substitution on the aromatic ring could cause many different effects on the reactivity of the chlorophenols for the different oxidation methods.

Based on the results obtained in this work, it can be concluded that the reactivity of the chorophenols decreases with the increasing substitution of the chlorine on the aromatic ring. The oxidation of the monochlorophenols was faster than that of the dichlorophenols, which were oxidized more easily than the trichlorophenol. The differences between the mono- and di-, between mono- and tri- as well as between monochlorophenols and trichlorophenol were statistically significant (ANOVATukey test). Increasing the degree of the $\mathrm{Cl}$ content decreases the solubility of the chlorophenols. As suggested by Tang and Huang [39], the increase in the hydrophobicity of the chlorophenols decreases the probability of the molecules encountered by the hydroxyl radical attack due to the non-dissolved CPs, resulting in an increase in the recombination rate of the hydroxyl radicals and, in consequence, a reduction in the oxidation rate of the organic compounds. Moreover, the increase of the chlorine atoms number in the molecules can block some favorable positions susceptible to the hydroxyl radical attack and, as a consequence, decrease the effectiveness of the chlorophenols oxidation [38].

The results showed also that the chlorine position of the chlorophenols has a significant effect on the degradation rate. The values of $k_{2}$ for 2-CP, 3-CP and 4-CP were $2.744,3.294$ and $2.982 \mathrm{~g} \mathrm{mmol}^{-1} \mathrm{~h}^{-1}$, respectively. At the 0.05 level, the differences of the $k_{2}$ values were significantly different. The removal of the 3-CP was faster than that of the 4-CP, which was degraded more easily than the $2-\mathrm{CP}$. The oxidation rate may be influenced by the interaction of the electron-withdrawing chlorine and the hydroxyl groups, the resonance of the phenolic anion and the steric effect of the chlorine. The attack of the free radicals is more favorable at the orthoand para-positions of the benzene ring structure. The chlorine atom at the orthoposition strongly inhibits the oxidation of the $\mathrm{C}-\mathrm{OH}$ to $\mathrm{C}=\mathrm{O}$ by the steric hindrance effect; while the $\mathrm{Cl}$ atom at the para- position might inhibit the oxidation of the $\mathrm{C}-\mathrm{Cl}$ to $\mathrm{C}=\mathrm{O}$ by both the $\sigma$-electron withdrawing conductive effect and 


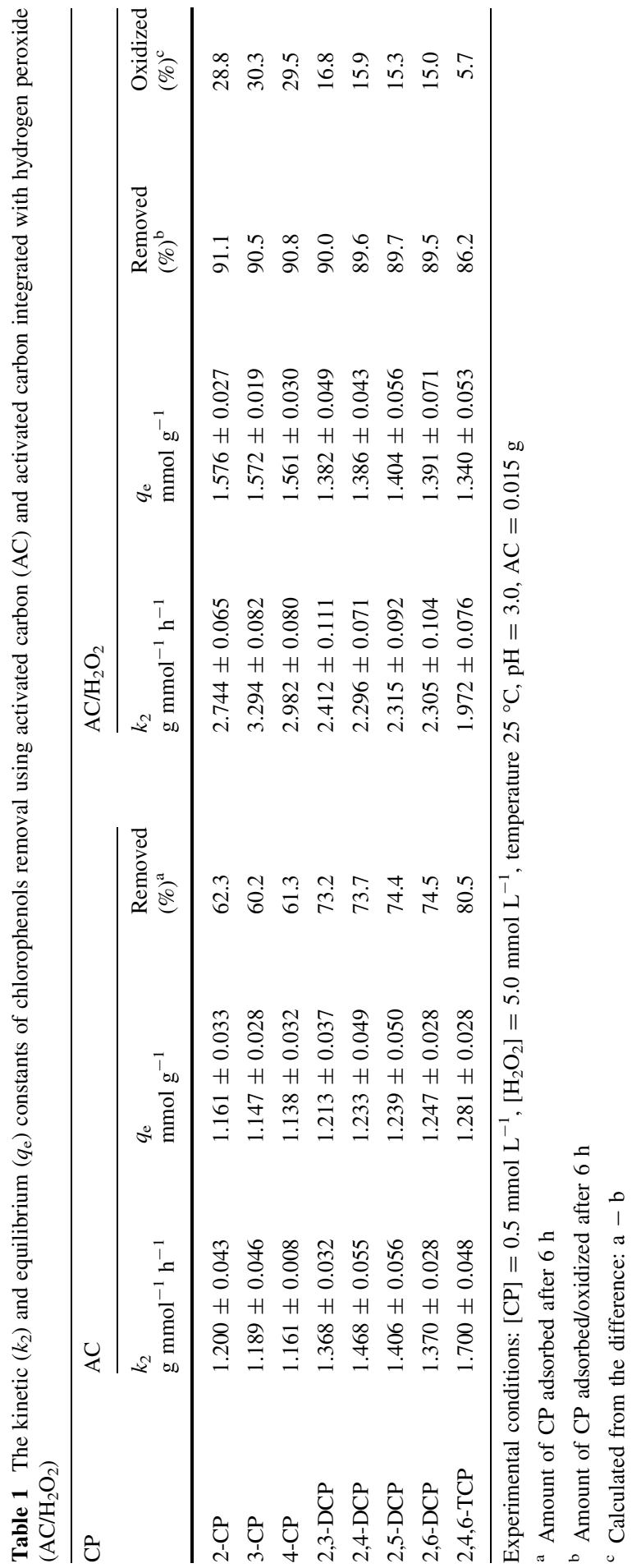


dechlorination [37]. Therefore, the higher degradation rate of the 3-CP is due to the fact that the benzene ring structure of the 3-CP provides one more site than those of 2-CP and 4-CP available for the free radical attack. A similar observation was reported by Tang and Huang [33] and by Zhou et al. [37]. Ku et al. [28] also reported that the decomposition rates of 3-CP by sonolysis were higher than those for the 2- and 4-chlorophenol. As shown in Table 1, 4-CP was removed faster than 2-CP by the $\mathrm{AC} / \mathrm{H}_{2} \mathrm{O}_{2}$. 2-Chlorophenol was more resistant than 4-CP because 2-CP have some steric hindrance effect due to the closer location between the $-\mathrm{OH}$ and the $-\mathrm{Cl}$ groups on the aromatic ring than that on 4-CP [33].

The oxidation rate of the dichlorophenols depends on the directory effect of the $-\mathrm{OH}$ and the $-\mathrm{CI}$ groups and the steric hindrance of the chlorine atoms [33]. The chlorine blocked at the ortho- position will decrease the dechlorination rate constants more than the chlorine atom blocked at the meta-position. The more $\mathrm{Cl}$ atoms existing on the aromatic ring especially at the ortho- and para-position makes the molecule more stable and more difficult for the oxidation [33]. The removal rate of the DCPs by the activated carbon in the presence of the $\mathrm{H}_{2} \mathrm{O}_{2}$ followed the sequence $2,3-\mathrm{DCP} \geq 2,5-\mathrm{DCP} \geq 2,6-\mathrm{DCP} \geq 2,4-\mathrm{DCP}$. The differences between all of the dichlorophenols were small and were not statistically significant.

It is found that 2,4,6-TCP was the most resistant to oxidation. This is due to the fact that the chlorine atoms in the molecule prevent the hydroxyl radical attack on the unoccupied sites of the aromatic ring.

The removal of the CPs by the $\mathrm{AC} / \mathrm{H}_{2} \mathrm{O}_{2}$ was a combination of oxidation and adsorption. In general, the degradation of the chlorophenols by the activated carbon integrated with the hydrogen peroxide was more effective and faster in comparison with the single AC adsorption. The differences in the $k_{2}$ and $q_{\mathrm{e}}$ values between the same chlorophenols obtained during their removal on the activated carbon and on the activated carbon in the presence of $\mathrm{H}_{2} \mathrm{O}_{2}$ were statistically significant $(p<0.05)$. Only the $q_{\mathrm{e}}$ values obtained for the 2,4,6-TCP adsorption $\left(1.281 \pm 0.028 \mathrm{mmol} \mathrm{g}^{-1}\right)$ and the adsorption integrated with $\mathrm{H}_{2} \mathrm{O}_{2}$ $\left(1.340 \pm 0.053 \mathrm{mmol} \mathrm{g}^{-1}\right)$ were not statistically significant $(p=0.166)$.

The percentage removal of 3-CP, after $6 \mathrm{~h}$, in the $\mathrm{AC} / \mathrm{H}_{2} \mathrm{O}_{2}$ was $90.5 \%(60.2 \%$ of the 3-CP was adsorbed and $30.3 \%$ was oxidized). Under the same experimental conditions, the removal of 2,4,6-TCP was found to be $86.2 \%$ (80.5\% was adsorbed and $5.7 \%$ was oxidized). This suggests that in the process, the adsorption played a dominant role.

The important part of the oxidative studies is identification of the oxidation products and intermediates. This is important because these compounds could also be toxic and moreover, their presence could affect the chlorophenols degradation rate and efficiency. A variety of reaction by-products were observed to form during the oxidation of chlorophenols (e.g. phenols, quinones, catechols) and the degradation pathways and mechanisms for many of the oxidation processes have been proposed [37, 40-44]. Unfortunately, in this work, during the oxidation experiments, the additional peaks on the chromatograms were not observed, suggesting that the oxidation intermediates were rapidly adsorbed on the activated carbon. The adsorption of the by-products formed during the oxidation of 
chlorophenols in $\mathrm{AC} / \mathrm{H}_{2} \mathrm{O}_{2}$ system was demonstrated by Huang et al. [19] who studied the relationship between the total reduction of 4-CP and dissolved organic carbon in suspension. They found that the decrease of dissolved organic carbon was similar to the total reduction of 4-CP, indicating that the chlorophenol and its oxidation by-products were almost adsorbed further onto activated carbon surface [19].

\section{Conclusions}

The removal of eight chlorophenols by the adsorption on the activated carbon and using activated carbon in the presence of $\mathrm{H}_{2} \mathrm{O}_{2}$ was investigated. The effects of the operational parameters including the $\mathrm{pH}$, activated carbon dosage and hydrogen peroxide concentration were studied. The influence of the chlorine position and the chlorine content in the chlorophenol molecules on their degradation were also studied. The results showed that the increasing of the degree of the chlorine substitution on the phenol ring increased the adsorption kinetics and the adsorption efficiency of the CPs on the activated carbon with the rate sequence of monochlorophenols $<$ dichlorophenols $<$ trichlorophenol. The integration of the activated carbon and the $\mathrm{H}_{2} \mathrm{O}_{2}$ treatment was more effective for the removal of the CPs than using the activated carbon alone. The chlorine content and the position on the aromatic ring had a significant effect on the chlorophenols removal. 3-CP was removed faster and more effectively than $4-\mathrm{CP}$, which was oxidized more easily than 2-CP. The CP degradation rate and degradation efficiency decreased with the increasing substitution of the chorine on the aromatic ring (mono- $>$ di$>$ trichlorophenol). The combination of both the adsorption and the heterogeneous catalysis $\left(\mathrm{AC} / \mathrm{H}_{2} \mathrm{O}_{2}\right)$ could be used as an eco-friendly process for wastewater treatment.

Open Access This article is distributed under the terms of the Creative Commons Attribution 4.0 International License (http://creativecommons.org/licenses/by/4.0/), which permits unrestricted use, distribution, and reproduction in any medium, provided you give appropriate credit to the original author(s) and the source, provide a link to the Creative Commons license, and indicate if changes were made.

\section{References}

1. Michałowicz J (2005) The occurrence of chlorophenols, chlorocatechols and chlorinated methoxyphenols in drinking water of the largest cities in Poland. Pol J Environ Stud 14:327-333

2. Michałowicz J, Stufka-Olczyk J, Milczarek A, Michniewicz M (2011) Analysis of annual fluctuations in the content of phenol, chlorophenols and their derivatives in chlorinated drinking waters. Environ Sci Pollut Res 18:1174-1183

3. Czaplicka M (2004) Sources and transformations of chlorophenols in the natural environment. Sci Total Environ 322:21-39

4. Igbinosa EO, Odjadjare EE, Chigor VN, Igbinosa IH, Emoghene AO, Ekhaise FO, Igiehon NO, Idemudia OG (2013) Toxicological profile of chlorophenols and their derivatives in the environment: the public health perspective. Sci World J 2013:1-11. Article ID 460215

5. Olaniran AO, Igbinosa EO (2011) Chlorophenols and other related derivatives of environmental concern: properties, distribution and microbial degradation processes. Chemosphere 83:1297-1306 
6. Pera-Titus M, Garcia-Molina V, Baños MA, Giménez J, Esplugas S (2004) Degradation of chlorophenols by means of advanced oxidation processes: a general review. Appl Catal B Environ 47:219-256

7. Dąbrowski A, Podkościelny P, Hubicki Z, Barczak M (2005) Adsorption of phenolic compounds by activated carbon-a critical review. Chemosphere 58:1049-1070

8. Soto ML, Moure A, Dominguez H, Parajo JC (2011) Recovery, concentration and purification of phenolic compounds by adsorption: a review. J Food Eng 105:1-27

9. Rodríguez-Reinoso F (1998) The role of carbon materials in heterogeneous catalysis. Carbon 36:159-175

10. Georgi A, Kopinke FD (2005) Interaction of adsorption and catalytic reactions in water decontamination processes Part I. Oxidation of organic contaminants with hydrogen peroxide catalyzed by activated carbon. Appl Catal B Environ 58:9-18

11. Klimenko NA, Savchina LA, Polyakova TV, Kozyatnik IP (2009) Adsorption-catalytic removal of fulvic acids on activated carbons in the presence of hydrogen peroxide. $\mathrm{J}$ Water Chem Technol 31(2):92-97

12. Santos VP, Pereira MFR, Faria PCC, Orfao JJM (2009) Decolourisation of dye solutions by oxidation with $\mathrm{H}_{2} \mathrm{O}_{2}$ in the presence of modified activated carbons. J Hazard Mater 162:736-742

13. Khorramfar S, Mahmoodi NM, Arami M, Bahrami H (2011) Oxidation of dyes from colored wastewater using activated carbon/hydrogen peroxide. Desalination 279:183-189

14. Dhaouadi A, Adhoum N (2010) Heterogeneous catalytic wet peroxide oxidation of paraquat in the presence of modified activated carbon. Appl Catal B Environ 97:227-235

15. Yeddou AR, Nadjemi B, Halet F, Ould-Dris A, Capart R (2010) Removal of cyanide in aqueous solution by oxidation with hydrogen peroxide in presence of activated carbon prepared from olive stones. Miner Eng 23:32-39

16. Bach A, Semiat R (2011) The role of activated carbon as a catalyst in GAC/iron oxide $/ \mathrm{H}_{2} \mathrm{O}_{2}$ oxidation process. Desalination 273:57-63

17. Wang G, Wu T, Li Y, Sun D, Wang Y, Huang X, Zhang G, Liu R (2012) Removal of ampicillin sodium in solution using activated carbon adsorption integrated with $\mathrm{H}_{2} \mathrm{O}_{2}$ oxidation. J Chem Technol Biotechnol 87:623-628

18. Lücking F, Köser H, Jank M, Ritter A (1998) Iron powder, graphite and activated carbon as catalysts for the oxidation of 4-chlorophenol with hydrogen peroxide in aqueous solution. Water Res 32(9):2607-2614

19. Huang HH, Lu MC, Chen JN, Lee CT (2003) Catalytic decomposition of hydrogen peroxide and 4-chlorophenol in the presence of modified activated carbons. Chemosphere 51:935-943

20. Kuśmierek K, Świątkowski A (2015) Degradation of 2-chlorophenol in aqueous solutions in presence of hydrogen peroxide and various carbon materials. Przem Chem 94(12):2126-2129

21. Khalil LB, Girgis BS, Tawfik TAM (2001) Decomposition of $\mathrm{H}_{2} \mathrm{O}_{2}$ on activated carbon obtained from olive stones. J Chem Technol Biotechnol 76:1132-1140

22. Aguinaco A, Pocostales JP, Garcia-Araya JF, Beltran FJ (2011) Decomposition of hydrogen peroxide in the presence of activated carbons with different characteristics. J Chem Technol Biotechnol $86: 595-600$

23. Kuśmierek K, Sankowska M, Skrzypczyńska K, Świątkowski A (2015) The adsorptive properties of powdered carbon materials with a strongly differentiated porosity and their applications in electroanalysis and SPME-GC. J Colloid Interface Sci 446:91-97

24. Lagergren S (1898) Theorie der sogenannten adsorption geloester stoffe. Vetenskapsakad Handl 24:1-39

25. Ho YS, McKay G (1999) Pseudo-second-order model for sorption processes. Process Biochem 34:451-465

26. Hameed BH, Chin LH, Rengaraj S (2008) Adsorption of 4-chlorophenol onto activated carbon prepared from rattan sawdust. Desalination 225:185-198

27. Kuśmierek K, Świątkowski A (2015) Influence of $\mathrm{pH}$ on adsorption kinetic of monochlorophenols from aqueous solutions on granular activated carbon. Ecol Chem Eng S 22(1):95-105

28. Ku Y, Tu YH, Ma CM (2005) Effect of hydrogen peroxide on the decomposition of monochlorophenols by sonolysis in aqueous solution. Water Res 39:1093-1098

29. Hamdaoui O, Naffrechoux E (2007) Modeling of adsorption isotherms of phenol and chlorophenols onto granular activated carbon. Part I: two-parameter models and equations allowing determination of thermodynamic parameters. J Hazard Mater 147:381-394 
30. Wu FC, Tseng RL, Huang SC, Juang RS (2009) Characteristics of pseudo-second-order kinetic model for liquid-phase adsorption: a mini-review. Chem Eng J 151:1-9

31. Liu QS, Zheng T, Wang P, Jiang JP, Li N (2010) Adsorption isotherm, kinetic and mechanism studies of some substituted phenols on activated carbon fibers. Chem Eng J 157:348-356

32. Hossain GSM, McLaughlan RG (2012) Sorption of chlorophenols from aqueous solution by granular activated carbon, filter coal, pine and hardwood. Environ Technol 33(16):1839-1846

33. Tang WZ, Huang CP (1995) The effect of chlorine position of chlorinated phenols on their dechlorination kinetics by Fenton's reagent. Waste Manag 15(8):615-622

34. Hossain SMG, McLaughlan RG (2012) Oxidation of chlorophenols in aqueous solution by excess potassium permanganate. Water Air Soil Pollut 223:1429-1435

35. Benitez FJ, Beltran-Heredia J, Acero JL, Rubio FJ (2001) Oxidation of several chlorophenolic derivatives by UV irradiation and hydroxyl radicals. J Chem Technol Biotechnol 76:312-320

36. Hugül M, Apak R, Demirci S (2000) Modeling the kinetics of UV/hydrogen peroxide oxidation of some mono-, di-, and trichlorophenols. J Hazard Mater B77:193-208

37. Zhou S, Gu C, Qian Z, Xu J, Xia C (2011) The activity and selectivity of catalytic peroxide oxidation of chlorophenols over $\mathrm{Cu}-\mathrm{Al}$ hydrotalcite/clay composite. J Colloid Interface Sci 357:447-452

38. Simon A, Ballai C, Lente G, Fábián I (2011) Structure-reactivity relationships and substituent effect additivity in the aqueous oxidation of chlorophenols by cerium(IV). New J Chem 35:235-241

39. Tang WZ, Huang CP (1996) Effect of chlorine content of chlorinated phenols on their oxidation kinetics by Fenton's reagent. Chemosphere 33:1621-1635

40. Hirvonen A, Trapido M, Hentunen J, Tarhanen J (2000) Formation of hydroxylated and dimeric intermediates during oxidation of chlorinated phenols in aqueous solution. Chemosphere 41:1211-1218

41. Lente G, Espenson JH (2004) A kinetic study of the early steps in the oxidation of chlorophenols by hydrogen peroxide catalyzed by a water-soluble iron(III) porphyrin. New J Chem 28:847-852

42. Zhou T, Li Y, Ji J, Wong FS, Lu X (2008) Oxidation of 4-chlorophenol in a heterogeneous zero valent iron/ $\mathrm{H}_{2} \mathrm{O}_{2}$ Fenton-like system: kinetic, pathway and effect factors. Sep Purif Technol 62:551-558

43. Kucharska M, Naumczyk J (2009) Degradation of selected chlorophenols by advanced oxidation processes. Environ Protect Eng 35(2):47-55

44. Biniak S, Świątkowski A, Pakuła A, Kuśmierek K, Trykowski G (2015) Electro-oxidation of chlorophenols on powdered carbon electrodes of different porosity. React Kinet Mech Cat 114:369-383 